\title{
Determination of thermal sensation levels for Koreans based on perceived temperature and climate chamber experiments with hot and humid settings
}

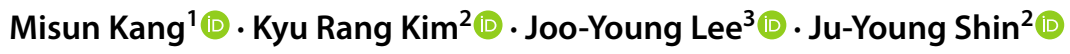

Received: 23 June 2021 / Revised: 10 February 2022 / Accepted: 23 February 2022 / Published online: 4 March 2022

(c) The Author(s) 2022

\begin{abstract}
People perceive thermal sensation differently despite the same temperature value of thermal comfort index depending on various factors such as climate, culture, and physiological characteristics. The use of the thermal comfort index without optimization may lead to biases in assessment of thermal stress and sensation. This study aims to derive the perceived temperature (PT) ranges of thermal sensation levels related to heat stress for Koreans. The experiments were designed using a controlled environmental chamber to derive the PT ranges and were performed with subjects who are residents of Seoul, South Korea. The experiments were carried out in the summers of 2017 and 2018, and the thermal sensation votes were surveyed from 19 subjects whose mean age, height, weight, and body mass index were 22.5 years, $171 \mathrm{~cm}, 72 \mathrm{~kg}$, and $23 \mathrm{~kg} \cdot \mathrm{m}^{-2}$, respectively. The derived PT ranges for Koreans led to a better performance than the reference PT ranges for Germans based on the results of validation. The thresholds of 'Warm,' 'Hot,' and 'Very hot' thermal sensation classes for Koreans were $28^{\circ} \mathrm{C}, 36^{\circ} \mathrm{C}$, and $43{ }^{\circ} \mathrm{C}$, respectively: higher than those for Germans. The results indicate that Koreans may have higher heat resistance or lower heat sensitivity than Germans.
\end{abstract}

Keywords Thermal sensation vote $\cdot$ Predicted mean vote $\cdot$ Thermal perception $\cdot$ Heat resistance $\cdot$ Thermal stress

\section{Introduction}

Thermal comfort can be explained as the balance of energy exchange between the human body and its environment (Gosling et al. 2014). Human thermal comfort is influenced by environmental factors such as temperature, humidity, wind speed, solar radiation, and mean radiant temperature (Budd 2008; Matzarakis et al. 1999). Additionally, human factors such as age, gender, physical activity, metabolic rate, and clothing are strongly associated with human

Kyu Rang Kim

krk9@kma.go.kr

1 Operational Systems Development Department, National Institute of Meteorological Sciences, Seogwipo-si, Republic of Korea

2 High Impact Weather Research Department, National Institute of Meteorological Sciences, Seogwipo-si, Republic of Korea

3 Department of Textiles, Merchandising and Fashion Design, College of Human Ecology, Seoul National University, Seoul, Republic of Korea thermal comfort (Nakano et al. 2002; Karjalainen 2012; Wang et al. 2018; Parsons 1999; Maykot et al. 2018). The use of various thermal comfort indices has been suggested, including perceived temperature (PT), physiological equivalent temperature (PET), and universal thermal climate index (UTCI), which are based on heat exchange between the human body and its thermal environment to evaluate biometeorological conditions (Jendritzky et al. 2012; Staiger et al. 2012, 2019; Höppe 1999). Since the thermal comfort index can take into account various factors in the assessment of thermal stress and sensation, it is swiftly becoming a mainstream metric of thermal environment assessment in scientific communities (Zhao et al. 2021). Use of the thermal comfort index can provide meaningful information for addressing economic and social issues including tourism (Rozbicka and Rozbicki 2020), planning of cities and urban design (Jänicke et al. 2019; Johansson and Emmanuel 2006), energy conservation (Yang et al. 2014), and public health (Urban and Kyselý 2014).

People perceive thermal sensation differently despite the same temperature value of thermal comfort index because thermal sensation varies with various factors such as climate, 
culture, and physiological characteristics (Lai et al. 2020; Cao et al. 2016; Jiang et al. 2019). Potchter et al. (2018) investigated the outdoor human thermal sensation in various climates and found that 'Neutral' sensation varies with the climatic condition in the region of interest. He et al. (2020) investigated cross-cultural thermal comfort differences in open spaces in a campus in Xi' an, China, for Chinese and Pakistani subjects. The ranges of 'Neutral' thermal sensations for Chinese and Pakistani subjects are different, as are their preferred actions for managing thermal discomfort. Kenawy and Elkadi (2021) examined the effects of cultural diversity on outdoor thermal perception in Melbourne, Australia. They reported that variations in thermal sensation votes are significantly related to the cultural and climatic backgrounds of the user. Thus, thermal comfort indices should be optimized for the accurate assessment of thermal stress and sensation (Ndetto and Matzarakis 2017; Sharmin et al. 2019). Pantavou et al. (2018) compared thresholds of thermal sensations for the UTCI and PET in different climatic regions and found that the threshold derived for the regions of interest would lead to a more accurate prediction of thermal comfort. Jeong et al. (2016) derived the PET range of 'Neutral' thermal sensation for Koreans using field measurements and questionnaires. This study did not investigate the other thermal sensations related to heat and cold stresses. Additionally, as this study derived thermal sensation based on field surveys, it may be difficult to correlate a specific environmental condition with the obtained results. Thus, the thermal comfort index ranges of thermal sensation levels related to heat and cold stresses are still absent for Koreans.

The PT is one of the predicted mean vote (PMV)-based thermal comfort indices (Staiger et al. 2012). The PT was developed based on the thermal sensations of Germans; as thermal sensations vary with various factors, particularly climate and culture, the use of PT without optimization may lead to biases in the assessment of thermal stress and sensation for people who live in other countries. Hence, the PT ranges of thermal sensation levels need to be derived for Koreans before its application for the assessment of thermal stress. Kang et al. (2020) nonetheless reported that the use of PT led to a better performance than the use of air temperature and wet-bulb globe temperature in the assessment of heat-related health risk in South Korea. The derivation of PT ranges of thermal sensation levels related to heat stress would provide a more accurate assessment of thermal stress and sensation in South Korea.

This study aims to derive the PT ranges of thermal sensation levels related to heat stress for Koreans. The experiments were designed to derive the PT ranges using a controlled environmental chamber and were performed upon subjects who are residents of Seoul, South Korea. The experiments were carried out in the summers of 2017 and 2018, and the thermal sensation votes (TSV) were collected from the subjects through a survey. New PT ranges of thermal sensation levels related to heat stress have thus been derived based on the surveyed TSVs. To the best of our knowledge, this is the first study to derive PT ranges of thermal sensation levels for Koreans. This study thus expects to improve our understanding of Korean physiological property to heatwave events. Additionally, the derived PT ranges for Koreans can lead to an improvement in the assessment of heat-related stress and health risks in South Korea.

\section{Materials and methods}

\section{Perceived temperature}

The perceived temperature (PT) is a thermal comfort index and is designed to assess the thermal physiology of people and is based on the 'Klima-Michel' model (KMM), which is an energy balance model for humans (Jendritzky et al. 1990). The PT is defined as 'the air temperature of a reference environment in which the thermal perception would be the same as in the actual environment' (Staiger et al. 2012). In the KMM for PT model, the reference person is a 35-yearold male with a height of $1.75 \mathrm{~m}$, a weight of $75 \mathrm{~kg}$, and a body surface area of $1.9 \mathrm{~m}^{2}$, an internal heat production of $135 \mathrm{~W} \cdot \mathrm{m}^{-2}$ (the metabolic rate of the reference person walking on flat ground at a speed of $4 \mathrm{~km} \cdot \mathrm{h}^{-1}$ ). The heat balance equation in KMM for the human body proposed by ASHRAE (2001) is as follows:

$\mathrm{M}-\mathrm{W}=\left(\mathrm{C}_{\mathrm{sk}}+\mathrm{R}_{\mathrm{sk}}+\mathrm{E}_{\mathrm{sk}}\right)+\left(\mathrm{C}_{\mathrm{res}}+\mathrm{E}_{\mathrm{res}}\right)+\mathrm{S}_{\mathrm{sk}}+\mathrm{S}_{\mathrm{cr}}$

Heat production within the body is related to the activity of the person. The human body consumes energy at the metabolic rate (M) so that it can do mechanical work (W), and the remainder of the metabolic rate $(\mathrm{M}-\mathrm{W})$ is the heat. Most of the energy released is in terms of heat: the heat transfer can be done by convection $(\mathrm{C})$, radiation $(\mathrm{R})$, and evaporation (E) through the skin (sk) and the respiratory system (res). The remaining heat is stored (S) in the skin and the core (cr) at a certain rate. For heat balance of the body, the rate of heat storage is zero $\left(\mathrm{S}_{\mathrm{sk}}=0\right.$ and $\left.\mathrm{S}_{\mathrm{cr}}=0\right)$. When the internal heat production is identical to the heat, which is exchanged with the external environment at a steady state, the PMV can be expressed by Eq. (2).

$\mathrm{PMV}=\alpha \cdot\left\{\mathrm{M}-\mathrm{W}-\left(\mathrm{C}_{\mathrm{sk}}+\mathrm{R}_{\mathrm{sk}}+\mathrm{E}_{\mathrm{sk}}\right)-\left(\mathrm{C}_{\mathrm{res}}+\mathrm{E}_{\mathrm{res}}\right)\right\}$

When calculating PT in KMM, the PMV equation modified by Gagge et al. (1986) was employed. Since the PMV accounts for energy exchange based on a two-node body model, latent and sensible heat transfer is from or to the skin 
(considering sweating) and by respiration. The PMV model includes main parameters influencing thermal sensation such as air temperature $\left(\mathrm{Ta},{ }^{\circ} \mathrm{C}\right)$, relative humidity $(\mathrm{RH}, \%)$, wind speed (WS, $\mathrm{m} \cdot \mathrm{s}^{-1}$ ), mean radiant temperature $\left(\mathrm{Tmrt},{ }^{\circ} \mathrm{C}\right.$ ), activity level, and clothing insulation $\left(\mathrm{I}_{\mathrm{c}}\right.$, clo). The activity level can be considered as a function of metabolic rate. The PT contains a clothing model, which automatically adapt to hot or cold conditions with a clothing insulation range between $\mathrm{I}_{\mathrm{cl}}=1.75$ clo (cold) and $\mathrm{I}_{\mathrm{cl}}=0.50$ clo (hot). In the heat stress condition where PMV is greater than zero, the $\mathrm{PT}$ is calculated by the following equation:

$\mathrm{PT}=6.18 \cdot \mathrm{PMV}+16.83$

Detailed information upon the calculation of PT can be found in Staiger et al. (2012).

In the present study, the PT inside the chamber was calculated using experimental environmental conditions, which are Ta, RH, WS, and the metabolic rates of subjects. When calculating PT inside the chamber, Tmrt was assumed to be equal to Ta. Additionally, the outside PT was calculated using data, which are the Ta, RH, WS, cloud amount, cloud type, and geographical information. The data were obtained from 27 meteorological stations of the Korea Meteorological Administration (KMA). The outside Tmrt was calculated using cloudiness information because measurements of solar radiation are conducted only at a few meteorological stations in KMA. The meteorological data cover summer months: June, July, August, and September over a 30-year period (from 1990 to 2019). The hourly PT values were calculated using hourly observed meteorological parameters, and the daily maximum PT values were collected to compare the proportions of thermal sensation classes by PT ranges. Details about the meteorological stations are presented in Fig. 1 and supplementary information.

\section{Experimental site and subjects}

In this study, all experiments were conducted in a controlled environmental chamber which has the capability to control ambient temperature with $\pm 0.5{ }^{\circ} \mathrm{C}$, and relative humidity with $\pm 3 \%$, of the Seoul National University in Seoul, South Korea. The chamber is a $6.5 \mathrm{~m} \times 3.6 \mathrm{~m} \times 2.8 \mathrm{~m}$ (width $\times$ length $\times$ height) room with external wall, door, and window (Fuji Medical Science, Japan) and is shown in Fig. 2. Seoul is located at $37.45^{\circ} \mathrm{N}$ and $126.95^{\circ} \mathrm{E}$ (NO. 5 in Fig. 1) and has hot and humid climate in the summer, which lasts from July to August. Over the summer of 30 years from 1990 to 2019, the mean and maximum Ta and mean RH were 25.7 and $34.6{ }^{\circ} \mathrm{C}$ and $74.9 \%$, respectively.

The experimental subjects were 11 and 9 young males who lived in Seoul in 2017 and 2018, respectively. They were healthy, i.e., not taking prescription medications

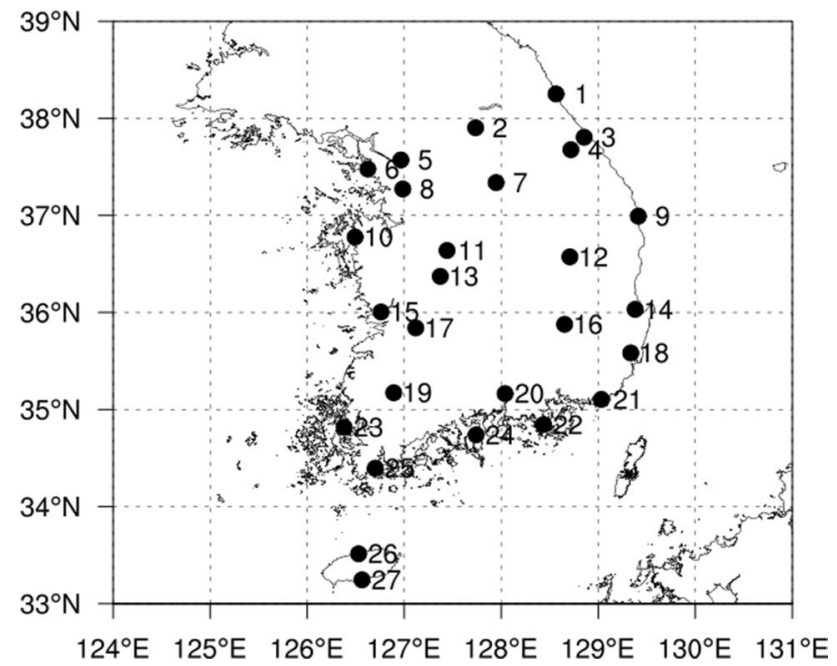

Fig. 1 Geographical locations of the employed stations. Detailed information of the employed 27 weather stations is presented in Table S1 of the supplementary information

and without cardiovascular or endocrine system diseases. The mean body mass parameters, such as age, height, weight, and body mass index (BMI) of the subjects in the 2017 experiment, were $23.5 \pm 2.3$ years, $167.2 \pm 7.0 \mathrm{~cm}$, $73.7 \pm 10.0 \mathrm{~kg}$, and $23.9 \pm 2.3 \mathrm{~kg} \cdot \mathrm{m}^{-2}$, respectively; for the subjects in the 2018 experiment, the mean body mass parameters were $21.3 \pm 2.6$ years, $175.2 \pm 4.0 \mathrm{~cm}$, $70.1 \pm 7.9 \mathrm{~kg}$, and $22.8 \pm 2.2 \mathrm{~kg} \cdot \mathrm{m}^{-2}$, respectively. The mean of the theoretical metabolic rates for all subjects was $137.8 \mathrm{~W} \cdot \mathrm{m}^{-2}$ (Jendritzky et al. 1990), and the difference between the metabolic rate of the reference person in the KMM and the mean of theoretical metabolic rate was very small. This fact supports the hypothesis that experimental results based on these subjects may have a similar thermal sense to that used in the development of PT. All subjects were sufficiently informed about the experimental purpose, experimental procedure, and measurements, and then they agreed to participate in the study. To attenuate any influences from human circadian rhythms for individual subjects, each subject participated in the experiment once a day from 09:00 to 12:00 Korea standard time (KST). Additionally, the experimental procedures were kept exactly the same for all the experiments, so as to ensure the comparability of the results. The subjects were asked to avoid caffeine, alcohol, and intense physical activity for at least $12 \mathrm{~h}$ prior to the experiment and were instructed to have breakfast at least $2 \mathrm{~h}$ prior to the experiment. Before the experiment, the subjects were asked to drink mineral water $(300 \mathrm{~mL})$ to avoid becoming dehydrated and to change their clothes to the uniform clothing provided by the researchers. 
Fig. 2 a Controlled environmental chamber, $\mathbf{b}$ temperature and relative humidity controller, and $\mathbf{c}$ a subject in the experiments
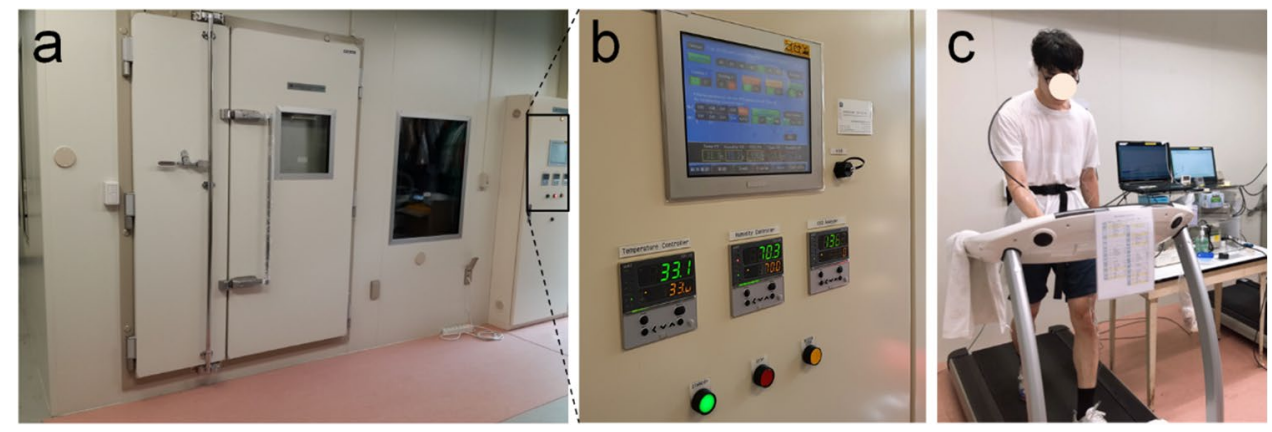

\section{Experimental design and conditions}

To assess the heat stress of Koreans, the experiments were carried out in the summers (June to August) of 2017 and 2018. The total experimental time of one trial for one subject was $70 \mathrm{~min}$, which included $10 \mathrm{~min}$ for rest and $60 \mathrm{~min}$ for activity. For the experiment, subjects were required to walk at $4 \mathrm{~km} \cdot \mathrm{h}^{-1}$ on flat, and clothing condition was $0.4-0.5$ clo, including short-sleeved t-shirts, short pants, underpants, socks, and sneakers as summer clothes. Additionally, the environmental conditions were set to simulate the summer climate in Korea, i.e., hot and humid atmosphere. In the chamber, the Ta was set to $30{ }^{\circ} \mathrm{C}$ and $35^{\circ} \mathrm{C}$ in 2017 and $28^{\circ} \mathrm{C}, 33^{\circ} \mathrm{C}$, and $38^{\circ} \mathrm{C}$ in 2018 , respectively. The RH was $70 \%$ and WS was lower than $0.005 \mathrm{~m} \cdot \mathrm{s}^{-1}$. The environmental conditions in the chamber were constant during the test period. Based on the experimental designs, $\mathrm{PT}$ values were $35^{\circ} \mathrm{C}$ and $44{ }^{\circ} \mathrm{C}$ in 2017 , and $31^{\circ} \mathrm{C}, 40{ }^{\circ} \mathrm{C}$, and $49{ }^{\circ} \mathrm{C}$ in 2018.

A psychological questionnaire was carried out to investigate the actual thermal feeling of subjects during the experiments. The questionnaire was designed to reflect the respondents' subjective assessment of the thermal environment. The subjects were required to report subjective responses, namely, the TSV. The term thermal sensation refers to the human thermal sense (feeling hot or cold, etc.). Considering the hot and humid conditions, a 9-point extended scale from ISO 10551 (ISO 1995) was used for the TSV. The scale of TSV used in this study is listed in Table 1. All experiments in 2017 and 2018 were set to the same experimental procedure, measurements, activity, and clothing conditions except for Ta in the environmental condition. The experimental process is briefly summarized in Fig. 3.

\section{Derivation of PT ranges of thermal sensation levels for Koreans}

The PT ranges of thermal sensation levels for Koreans were derived based on TSV that refers to responses for TSV from subjects in the 2017 experiment. There were exceptional
Table 1 Scales of thermal sensation vote

\begin{tabular}{ll} 
& level \\
\cline { 2 - 2 } Very hot & 4 \\
Hot & 3 \\
Warm & 2 \\
Slightly warm & 1 \\
Neutral & 0 \\
Slightly cool & -1 \\
Cool & -2 \\
Cold & -3 \\
Very cold & -4 \\
\hline
\end{tabular}

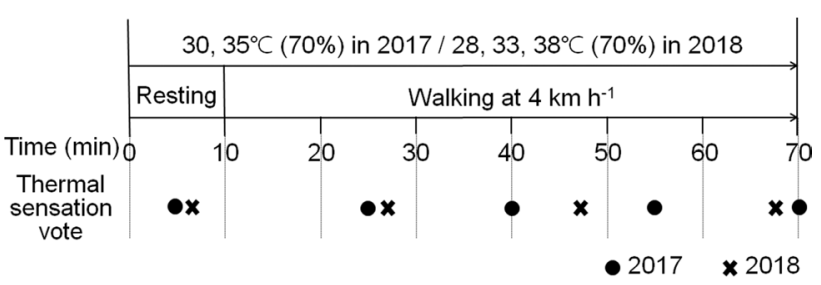

Fig. 3 Tabular representation of the experimental procedure. Circle and cross markers indicate time to obtain subject response for experiments in 2017 and 2018, respectively

heatwave events in the northern hemisphere as well as in South Korea in the summer of 2018 (Yiou et al. 2020; Larcom et al. 2019; Min et al. 2020; Im et al. 2019). Due to the fact that experiencing exceptional heat stress will lead to additional thermal adaptation, use of the 2018 data in deriving the PT ranges could lead to large biases. Therefore, data of the experiment in 2018 were only used to evaluate the appropriateness of the derived PT ranges. Thermal sensations differ among individuals even when they are in the same environment (Lin and Matzarakis 2008). Additionally, the mean $\mathrm{Ta}\left(25.4^{\circ} \mathrm{C}\right)$ during the summer of 2017 in Seoul was very close to the mean $\mathrm{Ta}\left(25.3^{\circ} \mathrm{C}\right)$ of summer over the 10 years (from 1999 to 2018 ) and corresponded to $54.5 \%$ in the distribution of the mean Ta of summer in Seoul. The 
mean $\mathrm{Ta}\left(26.6{ }^{\circ} \mathrm{C}\right)$ during the summer of 2018 in Seoul is much higher than the mean Ta of summer during the last 10 years, i.e., $95.1 \%$. Since there is a strong warming signal in Ta in South Korea (Shin et al. 2021), the Ta data during summer in the last 10 years were used in the calculation of the mean Ta to avoid global warming effects. Therefore, the mean TSV for each PT level was used in order to obtain the representativeness of the PT ranges. The linear regression model using mean TSV as the dependent variable and PT as the independent variable was fitted based on the data from the experiment. Finally, thermal sensation levels for Koreans were derived based on the fit linear regression model. The PT ranges of thermal sensations were considered to be thermal stress levels. In this study, the PT levels were optimized for heat stress of summer in South Korea.

The appropriateness of the new PT ranges of thermal sensation levels for assessing heat stress for Koreans was evaluated using the TSV from the subjects of the 2018 experiment. For comparison, the appropriateness of the reference $\mathrm{PT}$ ranges was also evaluated. The precision $(\mathrm{P})$, recall (R), F1 score (F), and accuracy (Acc) based on a confusion matrix with 5 classes were used as evaluation criteria. The confusion matrix in this study is two dimensions (class $i$ and j) and contains information about actual (class i) and predicted (class $\mathrm{j}$ ) classes which are divided from Class 0 to Class 4. Class 0 to 4 indicate 'Neutral' to 'Very hot' thermal sensation levels, respectively. In this study, class $i$ is TSV responses results that are obtained from the subjects in the 2018 experiment. The class $j$, namely predicted TSVs, is thermal sensation levels classified by reference and derived PT range in the 2018 experimental environment $\left(\right.$ PT $31^{\circ} \mathrm{C}$, $40^{\circ} \mathrm{C}$, and $49{ }^{\circ} \mathrm{C}$ ), respectively. In the confusion matrix, the total number of false negatives (TFN), false positives (TFP), true negatives $(T T N)$, and true positives (TTP) for each class $i$ can be calculated using Eqs. (4)-(7):

$$
\begin{aligned}
& \operatorname{TFN}_{i}=\sum_{\substack{j=0 \\
j \neq i}}^{4} x_{i j} \\
& \operatorname{TFP}_{i}=\sum_{\substack{j=0 \\
j \neq i}}^{x_{j i}} \\
& \operatorname{TTN}_{i}=\sum_{\substack{j \neq 0 \\
j \neq i}}^{4} \sum_{k=0}^{4} \begin{array}{c}
x_{j k} \\
\operatorname{TTP}_{i}=\sum_{i=0}^{4} x_{i i}
\end{array}
\end{aligned}
$$

where $x_{i j}$ is the number of scores corresponding to class $i$ for predicted TSV and class $j$ for TSV. TFN means a case in which the predicted TSV incorrectly predicts the positive
TSV, and TFP means a case in which the predicted TSV incorrectly predicts the negative TSV. Also, TTN means a case in which the predicted TSV correctly predicts the negative TSV, and TTP means a case in which the predicted TSV correctly predicts the positive TSV. The $P, R, F$, and Acc for each class $i$ can be calculated by following Eqs. (8)-(11):

$P_{i}=\frac{T T P_{i}}{T T P_{i}+T F P_{i}}$

$R_{i}=\frac{T T P_{i}}{T T P_{i}+T F N_{i}}$

$F_{i}=2 \times \frac{P_{i} \times R_{i}}{P_{i}+R_{i}}$

$\operatorname{Acc}_{i}=\frac{T_{T P}+T_{T N}}{\text { Totalnumberofdata }_{1}}$

\section{Results}

\section{PT ranges of thermal sensation levels for Koreans}

The relationship between PT and the mean subjective responses for each experimental condition of 2017 and 2018 is shown in Fig. 4. The result shows the mean and standard

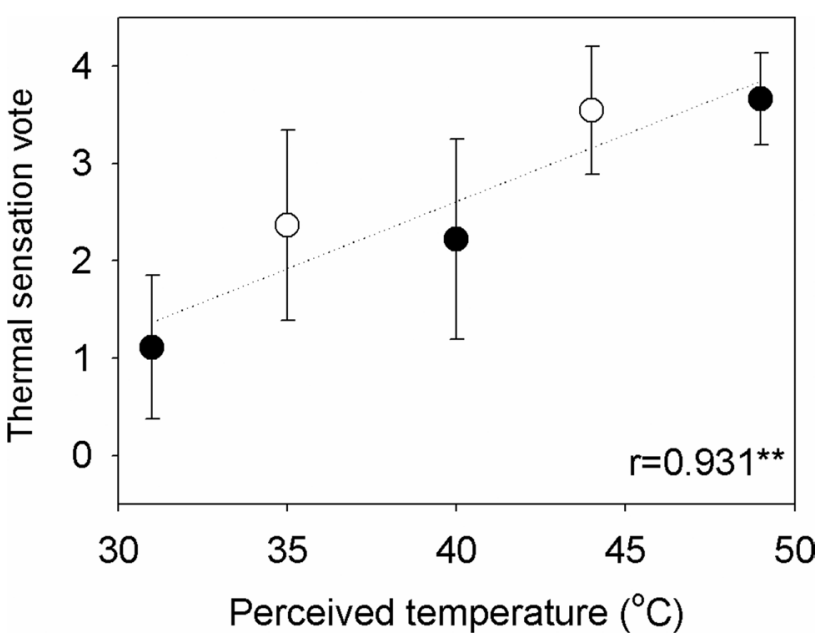

Fig. 4 The relationship between perceived temperature (PT) and the subjective responses of thermal sensation vote (TSV) for the experimental conditions of the 2017 (open circle) and 2018 (closed circle). The circle and bar indicate the mean and standard deviation, respectively, of the subjective responses of the subjects in each experimental condition. The PT of the experimental conditions correlated with the mean subjective responses. Note that $* *$ indicates that the Pearson correlation (r) estimates are significant with 5\% significance level 
deviation (SD) of each subjective response investigated at $55 \mathrm{~min}$. The closed and open circles indicate the subjective responses of TSV for the 2017 and 2018 experimental conditions, respectively. The TSV has a positive relationship with PT. The values of Pearson's correlation coefficient were 0.931 between TSV and PT and were statistically significant with 5\% significance level. The mean TSV increased from 1.11 to 3.67 with the increase of the PT. Above $40{ }^{\circ} \mathrm{C}$, subjects responded that TSV was 'hot' or 'very hot.' The results show that each subjective response varied with PT and subjects felt hotter with increasing PT. The relationships between PT and TSV, and between PT and the PMV from the 2017 experiment are illustrated in Fig. 5. A linear regression model was employed to describe the relationship between PT and TSV. The linear regression model was fitted using data of the 2017 experiment and is presented in Eq. (12).

$\mathrm{TSV}=0.13 \times \mathrm{PT}-2.03$

It can be assumed that the TSV from the subjects in this experiment represented the thermal sensations of Koreans.

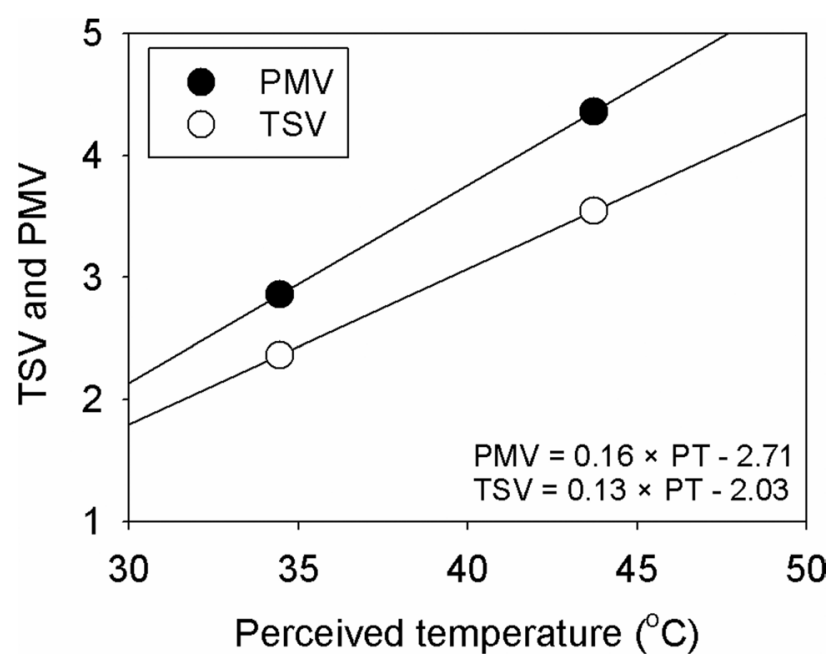

Fig. 5 Relationship between TSV and PT $(\mathrm{TSV}=0.13 \times \mathrm{PT}-2.03)$ and between PMV and PT $(\mathrm{PMV}=0.16 \times \mathrm{PT}-2.71)$. Open circles indicate the TSV that refers to responses for TSV from subjects in the 2017 experiment, and closed circles indicate the original PMV thermal sensation classes for the reference of the experiments
At the same values of PT, TSV was smaller than PMV, and the slope of the relationship between PT and TSV was smaller than that between PT and PMV (Fig. 5). As the PT increased by $1{ }^{\circ} \mathrm{C}$, the TSV increased by 0.13 . Since the PT range of thermo-physiological stress levels is equivalent to the PT range of thermal sensation, the derived PT ranges of thermal sensations were used as the PT ranges of thermal sensation classes for Koreans. The PT ranges of thermal sensation levels for Germans (the reference PT ranges) and Koreans are presented in Table 2.

The threshold of the 'Very hot' thermal sensation for Koreans was $43{ }^{\circ} \mathrm{C}$ and was larger than that $\left(38^{\circ} \mathrm{C}\right)$ for Germans. The thresholds for the 'Hot' and 'Warm' thermal sensations for Koreans were $36^{\circ} \mathrm{C}$ and $28^{\circ} \mathrm{C}$, respectively. These values were also higher than those for Germans $\left(32{ }^{\circ} \mathrm{C}\right.$ and $26{ }^{\circ} \mathrm{C}$, respectively). The range extents of 'warm' and 'hot' thermal sensations for Koreans were $8{ }^{\circ} \mathrm{C}$ and $7{ }^{\circ} \mathrm{C}$, respectively, and were likewise larger than those for Germans $\left(6^{\circ} \mathrm{C}\right)$. The threshold of the 'Slightly warm' thermal sensation was $20^{\circ} \mathrm{C}$ for both; however, the range extents for Koreans were broader than those for Germans. In summary, the thresholds of thermal sensation classes related to heat stress and the range extents were higher and wider, respectively, for Koreans than those for Germans. These results indicate that Koreans have higher thermal tolerance or lower thermal sensitivity than Germans in hot and humid environments.

\section{Comparison of the reference and Korean PT ranges of thermal sensation classes using experimental data in 2018}

The appropriateness of the new PT ranges of thermal sensation levels for assessing heat stress for Koreans was evaluated using the TSV from subjects in the 2018 experiment. For comparison, the appropriateness of the reference PT ranges was also evaluated. The new PT ranges are the derived PT range based on TSV from the subjects in the 2017 experiment, and the reference PT ranges are the original PT ranges for Germans (see Table 2). The confusion matrices for the reference and Korean PT ranges using the experiment data in 2018 are presented in Table 3. The observed TSV in Table 3 is the subjects' responses from the
Table 2 Perceived temperature ranges of thermal sensation class and thermo-physiological stress level for Germans and Koreans

\begin{tabular}{llll}
\hline Thermal sensation class & PT $\left(\right.$ Germans, $\left.{ }^{\circ} \mathrm{C}\right)$ & PT $\left(\right.$ Koreans, $\left.{ }^{\circ} \mathrm{C}\right)$ & $\begin{array}{l}\text { Thermo-physiologi- } \\
\text { cal stress level }\end{array}$ \\
\hline Very hot & $\mathrm{PT} \geq 38$ & $\mathrm{PT} \geq 43$ & Extreme heat stress \\
Hot & $32 \leq \mathrm{PT}<38$ & $36 \leq \mathrm{PT}<43$ & Great heat stress \\
Warm & $26 \leq \mathrm{PT}<32$ & $28 \leq \mathrm{PT}<36$ & Moderate heat stress \\
Slightly warm & $20 \leq \mathrm{PT}<26$ & $20 \leq \mathrm{PT}<28$ & Slight heat stress \\
Comfortable & $0 \leq \mathrm{PT}<20$ & $\mathrm{PT}<20$ & Comfort possible \\
\hline
\end{tabular}


Table 3 Confusion matrix between observed TSV and predicted TSVs based on the reference and derived PT ranges of thermal sensations. Classes 0 to 4 indicate 'Neutral' to 'Very hot' thermal sensation levels, respectively. TSV indicates responses results obtained from the subjects in the 2018 experiment, and the predicted TSVs indicate thermal sensation levels classified by reference and derived PT range based on the 2018 experimental environment $\left(\mathrm{PT} 31^{\circ} \mathrm{C}, 40^{\circ} \mathrm{C}\right.$, and $49^{\circ} \mathrm{C}$ ), respectively. Bold face indicates true positive cases

\begin{tabular}{|c|c|c|c|c|c|c|c|c|c|c|}
\hline \multirow[t]{3}{*}{ Observed TSV } & \multicolumn{10}{|c|}{ Predicted TSV } \\
\hline & \multicolumn{5}{|c|}{ by reference (German) PT range } & \multicolumn{5}{|c|}{ by derived (Korean) PT range } \\
\hline & Class 0 & Class 1 & Class 2 & Class 3 & Class 4 & Class 0 & Class 1 & Class 2 & Class 3 & Class 4 \\
\hline Class 0 & $\mathbf{0}$ & 0 & 2 & 0 & 1 & $\mathbf{0}$ & 0 & 2 & 1 & 0 \\
\hline Class 1 & 0 & $\mathbf{0}$ & 4 & 0 & 1 & 0 & $\mathbf{0}$ & 4 & 1 & 0 \\
\hline Class 2 & 0 & 0 & 3 & 0 & 2 & 0 & 0 & 3 & 2 & 0 \\
\hline Class 3 & 0 & 0 & 0 & $\mathbf{0}$ & 8 & 0 & 0 & 0 & 5 & 3 \\
\hline Class 4 & 0 & 0 & 0 & 0 & 6 & 0 & 0 & 0 & 0 & 6 \\
\hline
\end{tabular}

2018 experiment, whereas the predicted TSVs are thermal sensation levels based on the reference and Korean scales. For example, if a subject responded 'Slightly warm' at the experiment of PT $40{ }^{\circ} \mathrm{C}$, observed TSV is classified as Class 1 (Slightly warm), while the predicted TSVs are classified as Class 4 (Very Hot) or Class 3 (Hot) by reference scale or Korean scale, respectively. $P, R, F$, and $A c c$ for each class are listed in Table 4. The results indicated that the Korean PT ranges were more appropriate than the reference PT ranges in the assessment of thermal sensation level for Koreans in 2018. The Korean PT ranges performed better based on the chosen evaluation measures, except $P$. Although the average $P$ of the reference PT ranges is 0.73 , and this value is higher than that $(0.71)$ of the Korean PT ranges, the latter provided higher $P$ values than the reference for assessing the 'Very hot' thermal sensation class, which is equivalent to the 'Extreme heat stress' class in thermo-physiological stress levels and is important in assessing heat-related health risks. Overall, the average Acc of the Korean PT ranges is 0.8 and is higher than that (0.71) of the reference PT ranges. Large differences between observed TSV and predicted TSV for the reference PT ranges were observed in the 'Hot' and 'Very hot' thermal sensation classes. When the observed TSV indicated 'Hot,' the reference PT ranges predicted the 'Very hot' thermal sensation class for all subject responses. This result implies that thermal sensation classes are overestimated by the reference PT ranges for the 'Hot' thermal sensation class. Unlike the reference PT ranges, use of the Korean PT ranges improves accuracy in predicting thermal sensation classes for 'Hot' and 'Very hot.' For instance, $F$ increased from 0 to 0.59 for the 'Hot' thermal sensation class and from 0.5 to 0.8 for the 'Very hot' thermal sensation class by using the Korean PT ranges.

\section{Comparison of proportions of thermal sensation classes obtained by the reference and derived PT ranges in meteorological conditions during summer}

The frequency rates of each thermal sensation class based on the reference and Korean PT ranges for daily maximum PT in South Korea are presented in Fig. 6. The data of daily maximum PT covered summer months: June to September or May to September during 30 years (from 1990 to 2019) of 27 meteorological stations of KMA (see Fig. 1). Although summer in South Korea is generally considered June to September, the period from May to September is also accounted for due to the global warming that has led to increased number of heat-related illness cases in May. Also, although the experiments were conducted in the chamber located in Seoul, the derived PT range was applied across the country in South Korea as the PT range in the experiments represented the whole range of Korean summer climate.
Table 4 Evaluation results of the reference and derived PT ranges

\begin{tabular}{llllllll}
\hline \multirow{2}{*}{ Precision } & Version & Neutral & Slightly warm & Warm & Hot & Very hot & AVG \\
& Reference & 1.00 & 1.00 & 0.33 & 1.00 & 0.33 & 0.73 \\
\multirow{3}{*}{ Recall } & Derived & 1.00 & 1.00 & 0.33 & 0.56 & 0.67 & 0.71 \\
& Reference & 0.00 & 0.00 & 0.60 & 0.00 & 1.00 & 0.32 \\
& Derived & 0.00 & 0.00 & 0.60 & 0.63 & 1.00 & 0.45 \\
\multirow{3}{*}{ Accuracy } & Reference & 0.00 & 0.00 & 0.43 & 0.00 & 0.50 & 0.19 \\
& Derived & 0.00 & 0.00 & 0.43 & 0.59 & 0.80 & 0.36 \\
& Reference & 0.89 & 0.79 & 0.68 & 0.56 & 0.71 & 0.71 \\
& Derived & 0.89 & 0.79 & 0.68 & 0.74 & 0.89 & 0.80 \\
\hline
\end{tabular}




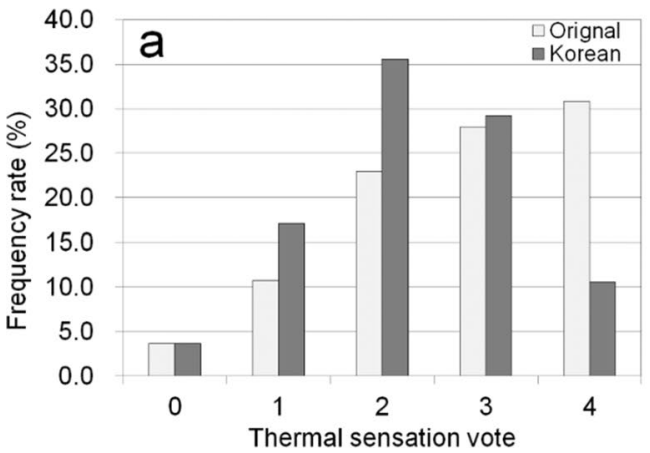

Fig. 6 The frequency rates distribution of thermal sensation classes using reference and Korean PT ranges for daily maximum PT (a) from June to September and (b) from May to September. Note that the daily maximum PT data covered over a 30-year period (from

For the period from June to September, the highest value (30.8\%) reached the 'Very hot' thermal sensation class based on reference PT ranges followed by 'Hot' (27.9\%), 'Warm' (23.0\%), 'Slightly warm' (10.8\%), and 'Neutral' (3.7\%). For the Korean PT ranges, the highest frequency rate (35.6\%) was of the 'Warm' thermal sensation class. The frequency rates of certain thermal sensations decreased as the difference from the 'Warm' thermal sensation class increased. The reference PT ranges led to overestimation of the 'Very hot' thermal sensation class as compared to the Korean PT ranges, while also leading to a large underestimation for the 'Warm' thermal sensation class. For the period starting May, although the frequency rate of the 'Warm' thermal sensation class had the highest value for the reference PT ranges, the frequency rate of the 'Very hot' thermal sensation class was still high. In the case of the Korean PT range, the 'Warm' thermal sensation class had the highest frequency rate. The frequency rates of 'Warm' and 'Very Hot' thermal sensation classes were higher and lower than those from June

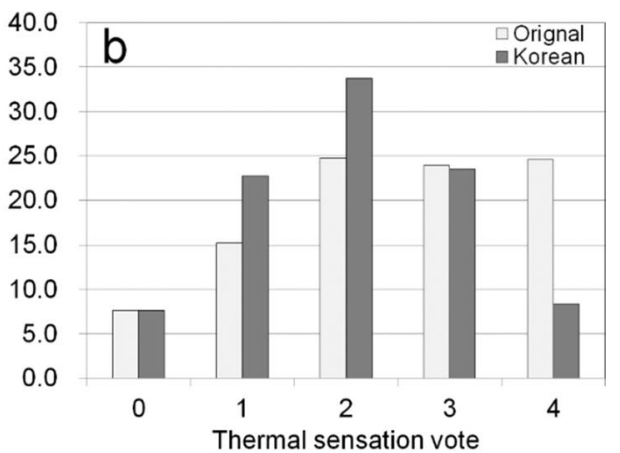

1990 to 2019) of 27 meteorological stations of KMA, and classes 0 , 1, 2, 3, and 4 indicate 'Neutral,' 'Slightly warm,' 'Warm,' 'Hot,' and 'Very hot' thermal sensations, respectively

to September, respectively. The distribution of thermal sensations based on reference PT ranges had a positively skewed shape, while the Korean PT ranges had a bell shape distribution.

In order to investigate the changes in frequency of thermal sensation classes during summer, the frequency rates of thermal sensations classes based on daily maximum PT, in 15-day intervals from May to September, were calculated (Fig. 7). There are discrepancies between the frequency rates of thermal sensation classes. The frequency rates of 'Very hot' and 'Hot' had high values in July and August for both the reference and Korean PT ranges; however, their values from the reference and Korean PT ranges were different. For the reference PT ranges, 'Very hot' appeared from early June to late September, and the proportions in late July and early August were $61.2 \%$ and $69.2 \%$, respectively. In contrast, 'Very hot' appeared from early July to early September based on the Korean PT ranges, and the proportions in late July and early August were $26.1 \%$ and $33.9 \%$, respectively.
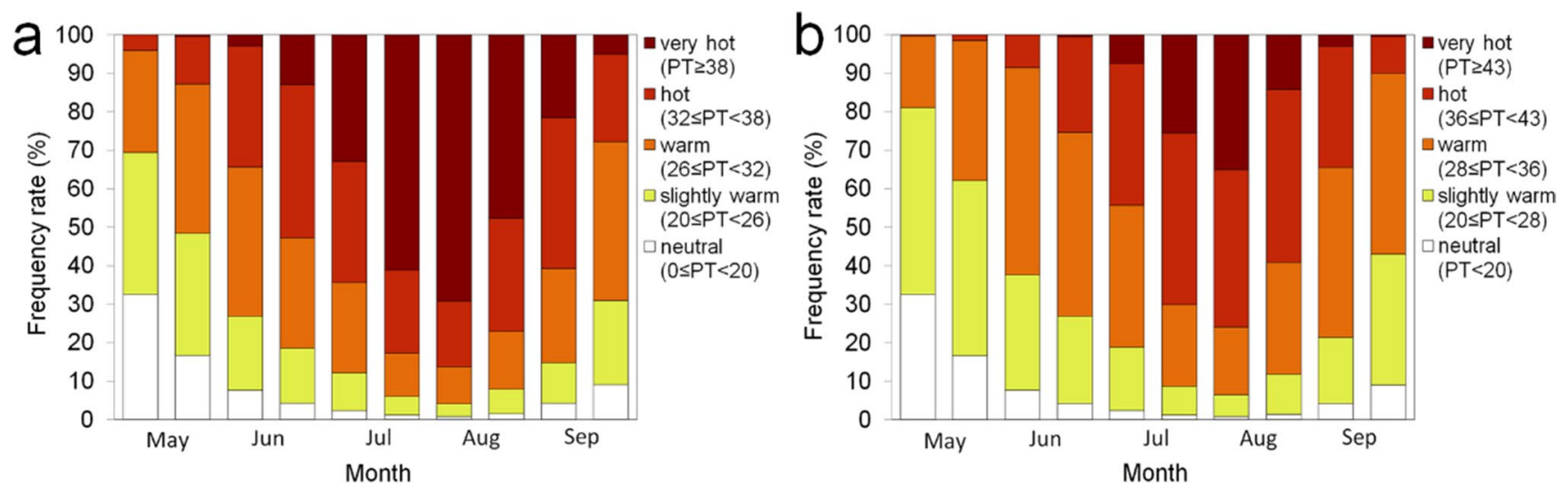

Fig. 7 The frequency rates of thermal sensation classes using (a) reference and (b) Korean PT ranges for daily maximum PT from May to September for 1990-2019 of 27 meteorological stations of KMA and presented in 15-day units 
In summary, the frequency rates for 'Warm' and 'Hot' thermal sensation classes were higher than those for reference PT ranges. The results imply that the reference PT ranges tend to overestimate thermal sensation classes related to heat stress in South Korea.

\section{Discussion}

Figure 8 shows the relationship between PT and the mean subjective responses for each experimental condition of 2017 and 2018, respectively. Results of experiments in 2017 and 2018 showed that prior experience of the subject to thermal environment influences on the subjective responses (also see Fig. 4). The environmental conditions of the experiment $\left(\mathrm{PT}=31^{\circ} \mathrm{C}, 41{ }^{\circ} \mathrm{C}\right.$, and $49^{\circ} \mathrm{C}$ ) in 2018 reached higher PT values than those $\left(\mathrm{PT}=35^{\circ} \mathrm{C}\right.$ and $\left.44{ }^{\circ} \mathrm{C}\right)$ in 2017 . The observed TSV showed positive relationships with PT in both experiments. The slope of the relationship between PT and TSV in the 2017 experiment was similar to that in the 2018 experiment. As the PT increased by $1{ }^{\circ} \mathrm{C}$, the TSV from the experiment in 2017 and 2018 increased by 0.13 and 0.14 , respectively (see Fig. 8). However, the Y-intercepts in 2017 and 2018 were -0.23 and -3.34 , respectively, and the TSVs from the experiment in 2018 seem to be approximately 1 smaller than those from the experiment in 2017 at the same PT level. As a matter of fact, exceptional heatwave events occurred in South Korea in the summer of 2018 (Im et al. 2019; Min et al. 2020), with the record long (31.5 days) heat wave and all-time high $\left(38.4{ }^{\circ} \mathrm{C}\right)$ temperature since the beginning of KMA observation in Seoul. Earlier studies reported that heat acclimation begins on the initial day of exposure and is complete after 7-10 days or 2 weeks (Eichna et al. 1945; Sawka et al. 1996; Pandolf 1998). The prior experience of the subjects to exceptional heatwave events led to their heat acclimation in 2018. Because this heat acclimation may have affected the heat resistance of the subjects, the TSVs from the subject responses in 2018 were smaller than those in 2017 at the same PT levels. Thus, the appropriate choice was to exclude the data in 2018 from deriving the
PT ranges for Koreans. If the experimental data in 2018 were used, the derived PT ranges may have had large biases and might not accurately represent the thermal sensations of Koreans in normal conditions.

In this study, the experimental data in 2018 were instead used to evaluate the appropriateness of the Korean PT ranges. The results showed that the Korean PT ranges derived from the experimental data in 2017 provided a robust performance, despite external factors that could disturb the thermal perception of the subjects. This evidence supports the hypothesis that the Korean PT ranges in this study can be used to assess thermal sensations of Koreans for extreme heatwave events.

The reference PT range currently used in Germany has been optimized using the fit linear regression model obtained from the relationship between PT and PMV (see Fig. 5). The PMV obtained using Eq. (2) represents thermal sensations for Germans, because this model was developed based on the physiological characteristics of Germans. The relationship between TSV and PT obtained by the chamber experiments in this study differs from the relationship between PT and PMV, which is not what would have been expected if the PMV equation successfully represents the thermal sensations for Koreans. The slope in the relationship between TSV and PT is lower than that in the relationship between PMV and PT (see Fig. 5). This difference leads to the difference of the PT range of thermal sensation classes related to heat stress for Germans and Koreans. The thresholds and the range extent for Koreans were higher and wider, respectively, than those for Germans (see Table 2). The results support the fact that the thermal sensations of Koreans and Germans are different. This difference may result from many factors: people's thermal sensations are associated with their climate, culture, clothing insulation, and age (Nakano et al. 2002; Wang et al. 2018; He et al. 2020). Firstly, the age of the subject and the reference person of KMM (PT model) are different. TSV is surveyed from the male subjects of their $20 \mathrm{~s}$, whereas PMV is calculated based on 35-year-old reference person. Previous studies showed different thermal sensation among age groups such as younger (their $20 \mathrm{~s}$ ) and
Fig. 8 The relationship between perceived temperature (PT) and the subjective responses of thermal sensation vote (TSV) for the experimental conditions of the (a) 2017 and (b) 2018. The black circle and bar indicate the mean and standard deviation, respectively, of the subjective responses of the subjects in each experimental condition. The PT of the experimental conditions correlated with the mean subjective responses
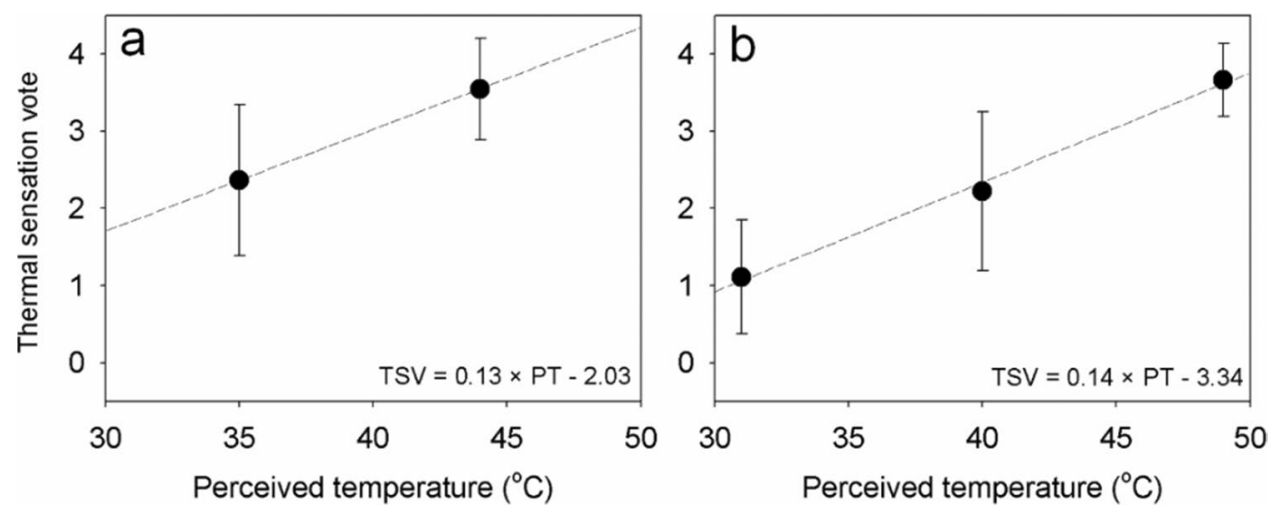
elderly (their 60-70 s) groups (Natsume et al. 1992; Wang et al. 2018). However, the difference in thermal sensation between those in their $20 \mathrm{~s}$ and $30 \mathrm{~s}$ could not be identified experimentally. Thus, it was assumed that there was no difference in the thermal sensation of their $20 \mathrm{~s}$ and $30 \mathrm{~s}$ in this study. In the case of the clothing insulation, as the clothing insulation (0.4-0.5 clo) of subjects in this study was similar to the clothing insulation ( 0.5 clo) for summer in the KMM (PT) model, so it should have not affected the difference between TSV and PMV. Lastly, summer in South Korea is hotter and more humid than in Germany. This high temperature and humid environment might lead to heat acclimation, which would eventually lead Koreans having higher heat resistance than Germans. Many studies focused on studying thermal comfort are based on Caucasian responses (Zhao et al. 2021). To expand the applicability of the thermal comfort index in other regions, the physiological characteristics for people in those regions should be investigated and the thermal comfort index should be modified according to the responses by the people of interest.

To reduce damages from the heat-related health risk and assess heat-related health risks for Koreans, it is critical to define appropriate thresholds of thermal sensation classes based on their physiological properties. Our experimental results showed the reference PT ranges overestimated the thermal sensation classes-particularly the 'Hot' thermal sensation class. These results lead to the inference that the reference PT ranges are inappropriate for assessing the thermal sensations of Koreans and bolster the need to derive new PT ranges. The derived PT ranges for Koreans provide a more accurate estimation of thermal sensations related to heat stress than the reference PT ranges. Therefore, the Korean PT ranges should be used in the assessment of heat-related health risks for Koreans to support decision and policy makers and in designing appropriate mitigation strategies, particularly for occupational health risks for outdoor workers.

To optimize the thermal sensations for people of interest based on the PT index, two approaches are possible. The first one is the modification of the PMV equation in the PT calculation, and the other is to derive new PT ranges for thermal sensations and stresses. The first approach changes the PT values and retains the PT ranges for thermal sensation classes and thermal stress levels. In contrast, the second approach of deriving new PT ranges retains the original PT values. The differences in PT values from the first approach could lead to confusion in the interpretation of the interactions between the thermal environment and the human body. By deriving new PT ranges, the physiological characteristics of the people of interest is taken into consideration in the assessment of thermal sensation and thermal stress. As a simple modification of the PT range may not fully represent physiological characteristics, the second approach may have a limited capacity to assess thermal stress. Nevertheless, because the PT is always a single value in a given environmental condition, the second approach can avoid confusion. Additionally, the PT values obtained by the second approach can be intercomparable among different environments. The $\mathrm{PT}$ index thus has the potential to be used as a universal index to measure the heat load of the environment to the human body. We thought that this property of PT would be important in the evaluation of its scientific robustness in the assessment of thermal stress and of the environment by intercomparing studies worldwide. Hence, this study adopted the second approach to develop a PT for Koreans in assessing thermal stress. The appropriateness of the two approaches should be discussed and examined in future research.

In the approach used in this study, the temperature calculated in the human thermal comfort or thermal stress model for human physiology (e.g., PT) is the same as the original model. In this study, the thermal stress level is compensated using the TSV-PT range relationship from the controlled environmental chamber experiments. The procedures for finding out a new PT range using observed TSV and onsite PT can be automated further by region, age, gender, or even individuals. The thermal sensation of any region and any group of people can be accurately evaluated in the end.

The vulnerability of people to heatwave events is strongly associated with age (Meade et al. 2020; Jiao et al. 2020; Ma et al. 2021). In particular, the elderly people are more vulnerable to heat-related health risks than young people at the same thermal exposure levels (Chen et al. 2015; Lee et al. 2018). Hence, a new PT model should be developed for different ages to assess heat-related health risks more accurately. Matzarakis et al. (2020) proposed the Klima-Michel Senior Model, which considers the physiological characteristics of elderly people in thermal stress assessments. It takes into account age-dependent changes in thermoregulation and a lower metabolic rate which corresponds to a male who is $1.75 \mathrm{~m}$ tall, weighs $70 \mathrm{~kg}$, is 70 years old, and has a walk speed of $0.28 \mathrm{~m} \cdot \mathrm{s}^{-1}$. The experiments performed in the current study were designed for young males. Hence, the derived PT ranges in this study may have a limited capacity to assess thermal sensations or heat-related stress on elderly people. To improve thermal stress assessments for Koreans, further experiments that take into account the physiological responses of elderly people to thermal stress should be carried out.

Moreover, there are revealed significant differences between the genders for thermal comfort (Karjalainen 2012; Indraganti and Humphreys 2021). Females express more dissatisfaction than males in the same thermal environments (Karjalainen 2012). In particular, some studies indicated that elderly women are more affected by extreme heat and heat-related mortality than men (van Steen et al. 2019; Tong et al. 2014). However, assessing heat-related health risks 
more accurately for women is difficult because the current PT model was designed only for males. Therefore, further experiments that take into account the physiological responses of women to thermal stress should be carried out. Additionally, a new PT model for women should be developed to assess heat-related health risks more accurately for women. The derived PT range for various groups of people including women and elderly people could be determined through the experiments similar to the method described in this study.

\section{Conclusions}

This study derived the Korean PT ranges of the thermal sensation classes related to heat stress based on the results of experiments using a controlled environmental chamber during summer in Seoul, South Korea. The PT ranges of thermal sensation classes were derived based on the TSV surveyed from the subjects. The Korean PT ranges were validated using data not used in the derivation and led to a better performance than the reference PT ranges for the assessment of thermal sensations of Koreans. While the reference PT ranges overestimated thermal sensations and thermo-physiological stress, particularly in the 'Hot' thermal sensation class, the Korean PT ranges provided robust predictions. The PT thresholds of 'Warm,' 'Hot,' and 'Very hot' thermal sensation classes for Koreans were $28^{\circ} \mathrm{C}, 36^{\circ} \mathrm{C}$, and $43^{\circ} \mathrm{C}$, respectively. The values of the thresholds for Koreans were higher than those for Germans, which implies that the thermal sensations of heat environments experienced by Koreans and Germans differ. The relationship between PT and PMV for Germans is different from the relationship between PT and TSV by Koreans. The slope in the relationship between TSV and PT is lower than that in the relationship between PMV and PT. This result indicates that Koreans may have higher heat resistance or lower heat sensitivity than Germans. Because new PT ranges were derived based on experiments for young people, the predicted thermal sensations and thermal stresses may have a limited ability to assess heat-related health risks for the elderly people who is more vulnerable to heatwave events. To improve our ability to assess heat-related risk, the PT ranges for elderly models should be derived in a future study. Since PT can be used to assess cold stress, and as cold-related health risk is vital in assessing thermal health risks, the PT ranges of cold-related thermal sensations and stresses must also be derived based on experiments using the experimental chamber to assess the whole range of thermal stresses for Koreans using the PT.

Supplementary Information The online version contains supplementary material available at https://doi.org/10.1007/s00484-022-02261-x.
Acknowledgements The authors thank to the Deutscher Wetterdienst (DWD) for providing the perceived temperature model by the cooperation activities between DWD and Korea Meteorological Administration and Dr. Gudrun Laschewski for giving insightful comments and kind supports.

Authors' contributions M.K. helped in data acquisition, modeling, analysis, visualization, writing - original draft preparation, and writing-review and editing, K.K. was involved in conceptualization, supervising, designing experiment, writing-original draft preparation, and writing - review and editing, J.L. contributed to designing and performing experiments, writing—review and editing, J.S. performed visualization, writing — original draft preparation, and writing - review and editing. All authors have read and agreed to the published version of the manuscript.

Funding This work was funded by the Korea Meteorological Administration Research and Development Program 'Development of Production Techniques on User-CustAQ2omized Weather information' under Grant (KMA2018-00622).

\section{Declarations}

Ethics approval This study received the approval from committee of the Seoul National University for the protection of human subjects (IRB No. 1707/001-001, IRB).

Competing interest The authors declare that they have no known competing financial interests or personal relationships that could have appeared to influence the work reported in this paper.

Open Access This article is licensed under a Creative Commons Attribution 4.0 International License, which permits use, sharing, adaptation, distribution and reproduction in any medium or format, as long as you give appropriate credit to the original author(s) and the source, provide a link to the Creative Commons licence, and indicate if changes were made. The images or other third party material in this article are included in the article's Creative Commons licence, unless indicated otherwise in a credit line to the material. If material is not included in the article's Creative Commons licence and your intended use is not permitted by statutory regulation or exceeds the permitted use, you will need to obtain permission directly from the copyright holder. To view a copy of this licence, visit http://creativecommons.org/licenses/by/4.0/.

\section{References}

ASHRAE (2001) ASHRAE Handbook: Fundamentals, vol 8. Thermal comfort. American Society of Heating, Refrigerating and AirConditioning Engineers, Atlanta

Budd GM (2008) Wet-bulb globe temperature (WBGT) — its history and its limitations. J Sci Med Sport 11(1):20-32. https://doi.org/ 10.1016/j.jsams.2007.07.003

Cao B, Luo M, Li M, Zhu Y (2016) Too cold or too warm? A winter thermal comfort study in different climate zones in China. Energy Build 133:469-477. https://doi.org/10.1016/j.enbuild.2016.09.050

Chen K, Bi J, Chen J, Chen X, Huang L, Zhou L (2015) Influence of heat wave definitions to the added effect of heat waves on daily mortality in Nanjing, China. Sci Total Environ 506-507:18-25. https://doi.org/10.1016/j.scitotenv.2014.10.092 
Eichna LW, Bean WB, Ashe WF, Nelson N (1945) Performance in relation to environmental temperature. Reactions of normal young men to hot, humid (simulated jungle) environment. Bull Johns Hopkins Hosp 76:25-58

Gagge AP, Fobelets A, Berglund L (1986) A standard predictive Index of human response to thermal environment. Trans Am Soc Heati Refriger Air-Condition Eng 92(2B):709-731

Gosling SN, Bryce EK, Dixon PG, Gabriel KMA, Gosling EY, Hanes JM, Hondula DM, Liang L, Bustos Mac Lean PA, Muthers S, Nascimento ST, Petralli M, Vanos JK, Wanka ER (2014) A glossary for biometeorology. Int J Biometeorol 58(2):277-308. https:// doi.org/10.1007/s00484-013-0729-9

Höppe P (1999) The physiological equivalent temperature - a universal index for the biometeorological assessment of the thermal environment. Int J Biometeorol 43(2):71-75. https://doi.org/10.1007/ s004840050118

He X, An L, Hong B, Huang B, Cui X (2020) Cross-cultural differences in thermal comfort in campus open spaces: A longitudinal field survey in China's cold region. Build Environ 172:106739. https:// doi.org/10.1016/j.buildenv.2020.106739

Im E-S, Thanh N-X, Kim Y-H, Ahn J-B (2019) 2018 summer extreme temperatures in South Korea and their intensification under $3{ }^{\circ} \mathrm{C}$ global warming. Environ Res Lett 14(9):094020. https://doi.org/ 10.1088/1748-9326/ab3b8f

Indraganti M, Humphreys MA (2021) A comparative study of gender differences in thermal comfort and environmental satisfaction in air-conditioned offices in Qatar, India, and Japan. Build Environ 206:108297. https://doi.org/10.1016/j.buildenv.2021.108297

ISO (1995) Ergonomics of the thermal environment. Assessment of the influence of the thermal environment using subjective judgement scales, vol 10551. International Standard Organization, Geneva

Jänicke B, Holtmann A, Kim KR, Kang M, Fehrenbach U, Scherer D (2019) Quantification and evaluation of intra-urban heat-stress variability in Seoul, Korea. Int J Biometeorol 63(1):1-12. https:// doi.org/10.1007/s00484-018-1631-2

Jendritzky G, Menz G, Schmidt-Kessen W, Schirmer H (1990) Methodik zur Räumlichen Bewertung der Thermischen Komponente im Bioklima des Menschen: Fortgeschriebenes KlimaMichel-Modell. Akademie für Raumforschung und Landesplanung, Beiträge 114, Hannover

Jendritzky G, de Dear R, Havenith G (2012) UTCI—Why another thermal index? Int J Biometeorol 56(3):421-428. https://doi.org/10. 1007/s00484-011-0513-7

Jeong M-A, Park S, Song G-S (2016) Comparison of human thermal responses between the urban forest area and the central building district in Seoul, Korea. Urban For Urban Green 15:133-148. https://doi.org/10.1016/j.ufug.2015.12.005

Jiang Y, Luo Z, Wang Z, Lin B (2019) Review of thermal comfort infused with the latest big data and modeling progresses in public health. Build Environ 164:106336. https://doi.org/10.1016/j.build env.2019.106336

Jiao Y, Yu H, Yu Y, Wang Z, Wei Q (2020) Adaptive thermal comfort models for homes for older people in Shanghai. China Energy Build 215:109918. https://doi.org/10.1016/j.enbuild.2020.109918

Johansson E, Emmanuel R (2006) The influence of urban design on outdoor thermal comfort in the hot, humid city of Colombo, Sri Lanka. Int J Biometeorol 51(2):119-133. https://doi.org/10.1007/ s00484-006-0047-6

Kang M, Kim KR, Shin J-Y (2020) Event-based heat-related risk assessment model for South Korea using maximum perceived temperature, wet-bulb globe temperature, and air temperature data. Int J Environ Res Public Health 17(8):2631. https://doi.org/ 10.3390/ijerph17082631

Karjalainen S (2012) Thermal comfort and gender: a literature review. Indoor Air 22(2):96-109. https://doi.org/10.1111/j.1600-0668. 2011.00747.x
Kenawy I, Elkadi H (2021) Effects of cultural diversity and climatic background on outdoor thermal perception in Melbourne city, Australia. Build Environ 195:107746. https://doi.org/10.1016/j. buildenv.2021.107746

Lai D, Lian Z, Liu W, Guo C, Liu W, Liu K, Chen Q (2020) A comprehensive review of thermal comfort studies in urban open spaces. Sci Total Environ 742:140092. https://doi.org/10.1016/j.scitotenv. 2020.140092

Larcom S, She P-W, van Gevelt T (2019) The UK summer heatwave of 2018 and public concern over energy security. Nat Clim Chang 9(5):370-373. https://doi.org/10.1038/s41558-019-0460-6

Lee D-G, Kim KR, Kim J, Kim B-J, Cho C-H, Sheridan SC, Kalkstein LS, Kim H, Yi S-M (2018) Effects of heat waves on daily excess mortality in 14 Korean cities during the past 20 years (1991-2010): an application of the spatial synoptic classification approach. Int J Biometeorol 62(4):575-583. https://doi.org/ 10.1007/s00484-017-1466-2

Lin T-P, Matzarakis A (2008) Tourism climate and thermal comfort in Sun Moon Lake, Taiwan. Int J Biometeorol 52(4):281-290. https://doi.org/10.1007/s00484-007-0122-7

Ma X, Tian Y, Du M, Hong B, Lin B (2021) How to design comfortable open spaces for the elderly? Implications of their thermal perceptions in an urban park. Sci Total Environ 768:144985. https://doi.org/10.1016/j.scitotenv.2021.144985

Matzarakis A, Mayer H, Iziomon MG (1999) Applications of a universal thermal index: physiological equivalent temperature. Int J Biometeorol 43(2):76-84. https://doi.org/10.1007/s004840050 119

Matzarakis A, Laschewski G, Muthers S (2020) The heat health warning system in Germany-application and warnings for 2005 to 2019. Atmosphere 11(2):170. https://doi.org/10.3390/atmos11020 170

Maykot JK, Rupp RF, Ghisi E (2018) Assessment of gender on requirements for thermal comfort in office buildings located in the Brazilian humid subtropical climate. Energy Build 158:1170-1183. https://doi.org/10.1016/j.enbuild.2017.11.036

Meade RD, Akerman AP, Notley SR, McGinn R, Poirier P, Gosselin P, Kenny GP (2020) Physiological factors characterizing heat-vulnerable older adults: a narrative review. Environ Int 144:105909. https://doi.org/10.1016/j.envint.2020.105909

Min S-K, Kim Y-H, Lee S-M, Sparrow S, Li S, Lott FC, Stott PA (2020) Quantifying human impact on the 2018 summer longest heat wave in South Korea. Bull Am Meteorol Soc 101(1):S103S108. https://doi.org/10.1175/bams-d-19-0151.1

Nakano J, Tanabe S-i, Kimura K-i (2002) Differences in perception of indoor environment between Japanese and non-Japanese workers. Energy Build 34(6):615-621. https://doi.org/10.1016/S03787788(02)00012-9

Natsume K, Ogawa T, Sugenoya J, Ohnishi N, Imai K (1992) Preferred ambient temperature for old and young men in summer and winter. Int J Biometeorol 36(1):1-4. https://doi.org/10.1007/ BF01208726

Ndetto EL, Matzarakis A (2017) Assessment of human thermal perception in the hot-humid climate of Dar es Salaam. Tanzania Int J Biometeorol 61(1):69-85. https://doi.org/10.1007/ s00484-016-1192-1

Pandolf K (1998) Time course of heat acclimation and its decay. Int J Sports Med 19(S2):S157-S160

Pantavou K, Lykoudis S, Nikolopoulou M, Tsiros IX (2018) Thermal sensation and climate: a comparison of UTCI and PET thresholds in different climates. Int J Biometeorol 62(9):1695-1708. https:// doi.org/10.1007/s00484-018-1569-4

Parsons KC (1999) International standards for the assessment of the risk of thermal strain on clothed workers in hot environments. Ann Occup Hyg 43(5):297-308. https://doi.org/10.1093/annhyg/ 43.5.297 
Potchter O, Cohen P, Lin T-P, Matzarakis A (2018) Outdoor human thermal perception in various climates: a comprehensive review of approaches, methods and quantification. Sci Total Environ 631-632:390-406. https://doi.org/10.1016/j.scitotenv.2018.02.276

Rozbicka K, Rozbicki T (2020) Long-term variability of bioclimatic conditions and tourism potential for Warsaw agglomeration (Poland). Int J Biometeorol. https://doi.org/10.1007/ s00484-020-01957-2

Sawka MN, Wenger CB, Pandolf KB (1996) Thermoregulatory Responses to Acute Exercise-Heat Stress and Heat Acclimation. In: Comprehensive Physiology. pp 157-185. https://doi.org/10. 1002/cphy.cp040109

Sharmin T, Steemers K, Humphreys M (2019) Outdoor thermal comfort and summer PET range: a field study in tropical city Dhaka. Energy Build 198:149-159. https://doi.org/10.1016/j.enbuild. 2019.05.064

Shin J-Y, Kim KR, Kim J, Kim S (2021) Long-term trend and variability of surface humidity from 1973 to 2018 in South Korea. Int J Climatol 41(8):4215-4235. https://doi.org/10.1002/joc.7068

Staiger H, Laschewski G, Grätz A (2012) The perceived temperature a versatile index for the assessment of the human thermal environment. Part A: scientific basics. Int J Biometeorol 56(1):165-176. https://doi.org/10.1007/s00484-011-0409-6

Staiger H, Laschewski G, Matzarakis A (2019) Selection of appropriate thermal indices for applications in human biometeorological studies. Atmosphere 10(1):18. https://doi.org/10.3390/atmos10010018
Tong S, Wang XY, Yu W, Chen D, Wang X (2014) The impact of heatwaves on mortality in Australia: a multicity study. BMJ Open 4(2):e003579. https://doi.org/10.1136/bmjopen-2013-003579

Urban A, Kyselý J (2014) Comparison of UTCI with other thermal indices in the assessment of heat and cold effects on cardiovascular mortality in the Czech Republic. Int J Environ Res Public Health 11(1):952-967. https://doi.org/10.3990/ijerph110100952

van Steen Y, Ntarladima A-M, Grobbee R, Karssenberg D, Vaartjes I (2019) Sex differences in mortality after heat waves: are elderly women at higher risk? Int Arch Occup Environ Health 92(1):3748. https://doi.org/10.1007/s00420-018-1360-1

Wang Z, de Dear R, Luo M, Lin B, He Y, Ghahramani A, Zhu Y (2018) Individual difference in thermal comfort: a literature review. Build Environ 138:181-193. https://doi.org/10.1016/j.buildenv.2018.04. 040

Yang L, Yan H, Lam JC (2014) Thermal comfort and building energy consumption implications - a review. Appl Energy 115:164-173. https://doi.org/10.1016/j.apenergy.2013.10.062

Yiou P, Cattiaux J, Faranda D, Kadygrov N, Jézéquel A, Naveau P, Ribes A, Robin Y, Thao S, van Oldenborgh GJ, Vrac M (2020) Analyses of the Northern European Summer Heatwave of 2018. Bull Am Meteorol Soc 101(1):S35-S40. https://doi.org/10.1175/ bams-d-19-0170.1

Zhao Q, Lian Z, Lai D (2021) Thermal comfort models and their developments: a review. Energy Built Environ 2(1):21-33. https://doi. org/10.1016/j.enbenv.2020.05.007 